\title{
Compreensão e produção oral de interrogativas- $Q$ em crianças portuguesas surdas com implante coclear
}

\author{
Mara Moita \& Maria Lobo \\ Centro de Linguística da Universidade Nova de Lisboa - Faculdade de Ciências Sociais e Humanas da \\ Universidade NOVA de Lisboa
}

\begin{abstract}
:
The present study investigates the comprehension and production of Portuguese wh-questions by hearing impaired children with cochlear implants. We investigate whether the asymmetries found in typically developing children are also present in our target group or whether the difficulties are more widespread. In particular, we investigate whether there are asymmetries between subject and (DP/PP) object wh-questions produced by these children, and whether wh-questions with a lexical restriction are more difficult than bare wh-questions. We also consider the importance of extra-linguistic variables, such as age of implantation, hearing age, early attendance of speech and language therapy sessions, and exposure to sign language.
\end{abstract}

Keywords: wh-questions, hearing loss, cochlear implant, language acquisition, critical period

Palavras-chave: interrogativas-Q, surdez, implante coclear, aquisição da linguagem, período crítico

\section{Introdução}

Um défice auditivo nos primeiros anos de vida resulta na privação à exposição de uma língua oral no período crítico em que esta deveria ser adquirida. Embora há muito se tenham identificado dificuldades sintáticas em crianças com défices auditivos (Quigley \& Paul, 1984; de Villiers, de Villiers \& Hoban, 1994, e.o.), apenas recentemente, com o aparecimento do implante coclear (IC), se estudam os efeitos da total privação auditiva durante o período crítico para a aquisição da linguagem.

$\mathrm{O}$ acesso tardio ao input linguístico tem sido indicado como o fator responsável pelas dificuldades sintáticas verificadas em crianças surdas com IC, em específico, na aquisição de dependências sintáticas com movimento (e.g. Friedmann \& Szterman, 2006). Esta hipótese tem sido sustentada pelo facto de os participantes fazerem uso de estruturas que não envolvem movimento como alternativa a estruturas com movimento de objeto (Friedmann \& Szterman, 2006; Friedmann \& Costa, 2011; Volpato \& Vernice, 2014; e.o.). As dificuldades verificadas em tarefas de compreensão, de produção e de repetição de estruturas interrogativas-Q em algumas crianças surdas com IC decorrerão desta incapacidade para estabelecer dependências resultantes de movimento (Friedmann \& Szterman, 2011). Considerando esta hipótese, o presente trabalho tem, como objetivo:

(i) verificar se existem assimetrias entre a aquisição de interrogativas-Q de sujeito (IS), de objeto direto (IOD) e de objeto preposicionado (IOP) em crianças surdas com IC;

(ii) compreender o impacto das variáveis extralinguísticas como a idade de ativação do IC, a intervenção precoce em TF e o tipo de exposição linguística (monolingue, bilingue, ou exposição à Língua Gestual Portuguesa como segunda língua (L2)) no desenvolvimento sintático, em específico no que diz respeito ao movimento do elemento-Q. 


\section{Período crítico e crianças surdas com implante coclear}

$\mathrm{Na}$ literatura, o período crítico para a aquisição da linguagem tem sido discutido, em particular, em contexto de aquisição de uma segunda língua, com foco na definição do período etário a que uma criança deverá ser exposta a uma língua para que esta seja adquirida sem esforço e de forma proficiente equiparadamente à sua língua materna. Em contexto de aquisição da língua materna, o período crítico tem sido definido com base na observação das diferentes etapas de aquisição da linguagem e na descrição dos diferentes efeitos linguísticos que resultam de isolamento ou de privação linguística.

A hipótese de um período crítico para a aquisição da linguagem foi inicialmente desenvolvida por Lenneberg (1967), que sugeriu que existe um período de tempo ideal em que a criança adquire uma língua através da simples exposição natural. $\mathrm{O}$ autor propôs que esse período decorre dos 2 anos de vida até à puberdade, período em que ocorre a maturação neuronal do cérebro. Posteriormente, outros estudos demonstraram que a aquisição da linguagem se inicia, desde logo, no período intrauterino, uma vez que, após algumas horas de nascimento, o recém-nascido já tem a capacidade de reconhecer frases da sua língua materna recorrendo a pistas prosódicas (Mehler et al., 1988) e que a sua perceção de vogais é condicionada pelo sistema a que foi exposto em vida intrauterina (Moon, Lagercrantz \& Kuhl, 2013; e.o.). No seguimento destes estudos, vários autores têm indicado que o processo de aquisição da linguagem é constituído por diferentes períodos críticos para cada área da linguagem (Ruben, 1997; Meisel, 2013; e.o.) e que a estabilização de algumas regras linguísticas é realizada em diferentes alturas durante a puberdade (e.g. Johnson \& Newport, 1989), aumentando a janela de oportunidade para a aquisição de uma língua e identificando diferentes períodos críticos para cada área da linguagem. Neste trabalho, abordaremos o período crítico para a aquisição da sintaxe, em específico o movimento do elemento-Q em interrogativas-Q, através de um estudo de compreensão e produção oral de crianças surdas com IC que estiveram totalmente privadas de input linguístico nos primeiros anos de vida.

Uma criança com privação auditiva nos primeiros anos de vida (e sem acesso a língua gestual) está sujeita a uma exposição tardia a uma língua, o que compromete o processo de aquisição e de desenvolvimento da linguagem. A colocação de um IC possibilita o restabelecimento da função da cóclea e permite às crianças com hipoacusia neurossensorial severa a profunda o acesso a input auditivo, promovendo a exposição e a aquisição da língua oral por via auditiva (Wilson \& Dorman, 2008; e.o.). Este acesso à exposição de uma língua oral por via do IC resulta no início do período de vida auditiva e, por conseguinte, determina o fim de uma privação total de input linguístico oral. Este contexto de privação linguística permite-nos explorar os efeitos da ausência de input linguístico durante o período crítico para a aquisição da linguagem.

Para diminuir o impacto desta privação auditiva, é necessário determinar, o mais cedo possível, as opções educacionais, linguísticas e clínicas a adotar, considerando os vários fatores sociolinguísticos de cada caso de surdez. Importa ainda salientar que a literatura sobre a aquisição e o desenvolvimento da língua oral na população infantil surda com IC tem apresentado vários fatores externos influenciadores do desenvolvimento linguístico destas crianças, tais como a idade de colocação do IC e o seu tempo de uso (idade auditiva), a intervenção precoce em terapia da fala (TF) e o tipo de exposição linguística através da(s) modalidade(s) linguística(s) adquirida(s), entre outros fatores.

A idade de colocação do IC parece ser a variável com mais impacto na aquisição e desenvolvimento linguístico oral e nas capacidades comunicativas verbais da população infantil implantada (Connor et al., 2000; Watson, Archbold \& Nikolopoulos, 2006; Friedmann \& Szterman, 2006; 2011). Embora a maioria dos estudos indique que as crianças surdas implantadas antes dos 2 anos de idade apresentam um melhor desempenho linguístico, esta população parece não atingir um desempenho considerado típico para a idade cronológica quando comparada com os seus pares ouvintes (Caselli et al., 2012; Hammer et al., 2014; 
Volpato \& Vernice, 2014; e.o.). No entanto, Svirsky e colegas (2004) consideram que a colocação do IC antes dos 2 anos de idade possibilitará que a criança surda tenha aos 6 anos de idade um desenvolvimento da linguagem semelhante ao dos seus pares ouvintes. Outros estudos têm demonstrado ainda que crianças surdas implantadas antes dos 3 anos de idade atingem os mesmos níveis de performance linguística em comparação com os seus pares ouvintes após 5 anos de uso de IC (Connor et al., 2006; Geers, Nicholas \& Sedey, 2003; e.o.). Estudos mais recentes e focados no domínio de estruturas sintáticas complexas indicam que a implantação em conjunto com uma intervenção precoce em TF no primeiro ano de vida parece contribuir para uma aquisição sintática equiparada à da população infantil ouvinte (Friedmann \& Szterman, 2006; 2011).

A intervenção precoce em TF tem sido desde há muito estudada tanto na população infantil com perda auditiva como em outros tipos de população (Yoshinaga-Itano et al., 1998; Friedmann \& Szterman, 2006; e.o.). São muitos os estudos que indicam que as crianças surdas implantadas que usufruíram de uma intervenção precoce em TF apresentam num curto período de tempo de uso de IC melhores desempenhos linguísticos em tarefas de perceção, de discriminação, de repetição e de produção da língua oral em comparação com as crianças surdas implantadas que não usufruíram de uma intervenção precoce em TF no mesmo período (Detman,Wall, Constantinescu \& Dowell, 2013; Friedmann \& Szterman, 2011; MayMederake, 2012; e.o.).

O impacto do tipo de exposição linguística tem sido também indicado como um fator externo pertinente no desenvolvimento linguístico oral na população infantil surda após a colocação do IC. Para estudar a(s) modalidade(s) linguística(s) adquirida(s), é necessário discriminar, pelo menos, dois tipos de população infantil com IC: (i) monolingues orais, crianças expostas a apenas uma língua oral falantes dessa língua; e ii) bilingues bimodais, crianças expostas a uma língua gestual e a uma língua oral, sendo gestuantes e falantes de ambas as modalidades linguísticas. Vários são os estudos que indicam que as crianças surdas com IC apresentam melhores resultados ao nível de perceção do discurso e do aumento de vocabulário quando expostas apenas a uma língua oral ou com pouca exposição à língua gestual (Geers et al., 2017; Geers, Nicholas, Tobias \& Davidson, 2016), defendendo a ideia de que a língua gestual não incita a um melhor desempenho linguístico oral nesta população (Geers, Nicholas \& Sedey, 2003). Por outro lado, alguns estudos referenciam que as crianças surdas com IC bilingues bimodais apresentam melhores desempenhos linguísticos ao nível da expressão oral e do vocabulário em comparação com os seu pares monolingues orais (Connor et al., 2000; Davidson, Lillo-Martin \& Pichler, 2014).

Considerando a pertinência destes três fatores externos, o presente estudo analisará o impacto destas variáveis no desenvolvimento sintático de crianças surdas com IC através de tarefas de compreensão e de produção de interrogativas-Q.

\section{Aquisição do movimento-Q e de interrogativas-Q}

Estudos sintáticos realizados em crianças surdas com dispositivos auditivos (próteses auditivas e IC) têm indicado um défice sintático nesta população associado à compreensão e à produção de dependências sintáticas que envolvem movimento sintático (Friedmann \& Szterman, 2006, 2011; Friedmann \& Costa, 2011; e.o.). Considerando que as interrogativas-Q ocorrem desde cedo no discurso da população infantil ouvinte (Soares, 2006) e que estas estruturas no português europeu (PE) podem ser produzidas com um movimento sintático do constituinte-Q para a periferia esquerda, analisaremos, neste estudo, como se processa a aquisição de interrogativas-Q em crianças surdas com IC a adquirir o PE.

Assim, importa referir que, nas interrogativas-Q do PE, o constituinte-Q pode ocorrer in situ (1a), ou seja, na sua posição argumental, ou pode ocorrer deslocado para a periferia esquerda da frase (1b) e (1c) (Amaral, 2009). 
(1) a. A avó está a beijar [quem]?

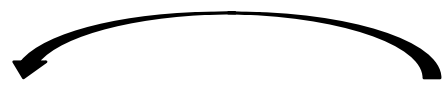

b. [Quem] $]_{i}$ é que a avó está a beijar

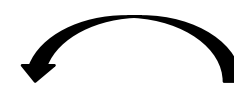

c. $[\text { Quem] }]_{i}$ é que ti está a beijar a avó?

Esta ocorrência do elemento-Q na posição à esquerda da frase é originada por uma operação derivacional proposta pela Teoria de Princípios e Parâmetros, o movimento-Q, cuja realização na componente sintática está sujeita a parametrização. Seguindo esta proposta, no contexto das interrogativas-Q, o sintagmaQ é movido para a posição não argumental de especificador da categoria funcional de CP ([Spec, CP)] de forma a verificar o traço $[u \mathrm{Wh}]$ (Pesetsky \& Torrego, 2001; Soares, 2006), deixando um vestígio na sua posição inicial. Este movimento caracteriza-se como um movimento do tipo A-barra (Friedmann \& Lavi, 2006). Além do movimento de constituintes para CP (do constituinte-Q para [Spec, CP]), pode haver também movimento do verbo flexionado para $\mathrm{C}^{\mathrm{o}}$ ou inserção de é que. O movimento do constituinte-Q dá origem a uma cadeia A-barra, sendo a cauda da cadeia a posição em que é atribuído o papel temático. Para uma interpretação adequada da frase, terá de ser estabelecida essa relação de dependência entre o elemento movido e a posição de base.

No contexto de aquisição de interrogativas-Q, verifica-se que a ocorrência de interrogativas-Q em línguas em que o constituinte-Q tanto pode ocorrer in situ como se pode mover para a periferia esquerda da frase encontra-se desde cedo no discurso de crianças ouvintes com desenvolvimento típico (Sell, 2002; Grolla, 2005; Augusto, 2005; Soares, 2006). Os estudos não só registam uma predominância de interrogativas com movimento-Q em detrimento de interrogativas in situ em idades precoces (Grolla, 2005; Soares, 2006) como também indicam que as interrogativas-Q são das primeiras estruturas com movimento de constituintes a serem produzidas (Soares, 2004; Grolla, 2005). Contudo, a literatura revela uma aquisição assimétrica de interrogativas-Q, demonstrando que as interrogativas de objeto (IO) (1b) são adquiridas mais tardiamente que as interrogativas de sujeito (IS) (1c), tal como acontece na aquisição de orações relativas de sujeito versus orações relativas de objeto (Ferreira, 2008; Costa et al., 2009; Costa, Lobo e Silva, 2011, e.o.). As dificuldades encontram-se sobretudo em interrogativas de objeto com movimento-Q e com restrição lexical ou $d$-linked (e.g. que menino) e em relativas de objeto com antecedente, não se manifestando da mesma forma em orações interrogativas sem restrição lexical ou não $d$-linked (quem). Estas dificuldades têm sido explicadas (Friedmann, Belleti \& Rizzi, 2009; Grillo, 2008, 2009) como decorrendo de Minimalidade Relativizada: a intervenção de um constituinte que partilha traços semelhantes com o constituinte movido levaria a dificuldades no estabelecimento da cadeia entre elemento movido e posição de base. Estas assimetrias foram identificadas na aquisição de muitas línguas (cf. Sauerland et al., 2016; Friedmann, Rizzi \& Belletti, 2016, Guasti, Brachini \& Arozio, 2012).

Também na aquisição de interrogativas do PE, as crianças ouvintes com desenvolvimento típico (dos 3;00 aos 5;11 de idade) apresentam uma assimetria entre IS e IO na produção e na compreensão de interrogativas $d$-linked, mas não na compreensão de interrogativas não d-linked (Cerejeira, 2009; Baião, 2012), atingindo na idade dos 5;00-5;11 acertos superiores a 60\%. Baião (2012) verifica ainda que não há diferenças significativas entre a aquisição de IOD e de interrogativas de objeto preposicionado (IOP), o que mostra que a presença da preposição não facilita a compreensão destas estruturas, à semelhança do que outros 
estudos mostraram para orações relativas de objeto e de objeto preposicionado (Costa, Friedmann, Silva e Yachini, 2014, 2015).

Os primeiros estudos sobre a aquisição de interrogativas-Q em crianças surdas sem dispositivos auditivos indicam a existência de dificuldades na compreensão e no juízo de gramaticalidade destas estruturas avaliadas através de tarefas de leitura e de escrita, por parte desta população (Quigley, Wilbur \& Montanelli, 1974, citado por Friedmann e Szterman, 2011). A existência de assimetrias entre as IS e as IO é também encontrada em Berent (1996), que analisa a produção escrita destas estruturas no mesmo tipo de população surda sem dispositivos auditivos. Nestes estudos, a privação de input linguístico oral é apontada como a causa para estes défices sintáticos, que são considerados irreversíveis se não existir uma intervenção específica oral ou a colocação de um dispositivo auditivo.

O estudo de Friedmann \& Szterman (2011) é até ao momento o único que analisa objetivamente as capacidades de compreensão e de produção oral de interrogativas-Q em 11 crianças surdas dos 9;01 aos 12;04 anos de idade cronológica com dispositivos auditivos (próteses auditivas e IC) com períodos entre 1;09 aos 10;09 anos. Com o objetivo de verificar se as crianças com défice em orações relativas de objeto também apresentam dificuldades em IO, as autoras aplicaram como rastreio as tarefas de relativas de um estudo anterior (Friedmann \& Stzerman, 2006) e em seguida aplicaram as tarefas de compreensão e de produção oral de interrogativas. Verifica-se que, da amostra de 18 crianças surdas com próteses auditivas e com IC, 7 apresentam bons desempenhos na compreensão e na produção de orações relativas de objeto. As restantes 11 crianças revelaram desempenhos significativamente abaixo do grupo de controlo com diferenças significativas em interrogativas $d$-linked, mas sem diferenças significativas em interrogativas não $d$-linked. As interrogativas de sujeito e a omissão de caso acusativo foram as estruturas mais produzidas na condição IO pelos participantes.

Embora os resultados de Friedmann \& Szterman (2011) revelem que as crianças surdas com dispositivos auditivos apresentam défices no processamento de estruturas com movimento-Q, a produção oral destas estruturas tem sucesso nas 7 crianças excluídas inicialmente do estudo e com valores acima de 50\% (69\%). Por conseguinte, poder-se-á assumir que o movimento-Q não está totalmente comprometido pela privação linguística nos primeiros anos de vida nestas crianças. Esta ideia é suportada pela observação de interrogativas-Q no discurso espontâneo de crianças surdas portuguesas com IC (Moita, 2015). Neste estudo exploratório, verifica-se que tanto as IS como as IO, incluindo interrogativas-Q com movimento do sintagma preposicional, estão presentes no discurso espontâneo de crianças surdas monolingues com colocação do IC a partir dos 2 anos de idade.

Tendo em consideração as características do movimento sintático subjacente às interrogativas-Q, que se apresentam precocemente no discurso da população infantil ouvinte, ainda que com assimetrias conforme o tipo de interrogativa e o tipo de constituinte movido, este estudo experimental testa a produção e a compreensão de IS, IOD e IOP $d$-linked e não $d$-linked em crianças portuguesas surdas com IC.

\section{Metodologia}

Com este estudo, pretende-se verificar se o facto de as crianças surdas com IC estarem privadas, nos primeiros anos de vida, de input linguístico resulta em dificuldades generalizadas na aquisição de estruturas com movimento-Q ou se há diferenças em função do tipo de interrogativa (d-linked vs. não $d$-linked) e da função sintática do constituinte interrogativo (sujeito, OD e OP). Para o efeito será estudada a aquisição de interrogativas-Q em crianças surdas com IC que estão a adquirir o português. Procedeu-se à aplicação de um teste de produção induzida oral e dois testes de compreensão de interrogativas-Q de sujeito, de objeto direto e de objeto preposicionado. 
Tendo em conta a heterogeneidade de fatores externos que podem condicionar o desempenho da população-alvo, serão estudadas outras variáveis que, na literatura, têm demonstrado ter impacto no desempenho linguístico destas crianças: idade de ativação do IC; intervenção precoce em TF; e o tipo de exposição linguística (monolingue, bilingue e exposição à LGP como L2).

\section{a. . Amostra}

A população-alvo para este estudo foi selecionada com base num conjunto de critérios de inclusão considerando os vários tipos de hipoacusia e os diferentes fatores externos com impacto no percurso linguístico de cada criança indicados na literatura. Para este trabalho, a amostra é constituída por crianças surdas com surdez neurossensorial profunda e/ou severa bilateral pré-linguística que não tiveram qualquer benefício auditivo com o uso de PA no período pré-IC. Todas as crianças são falantes do PE e filhas de pais portugueses. Só participaram no estudo as crianças que apresentavam uma idade auditiva entre os 2;00 e os 14;11, de forma a contemplar o período para a maturação linguística proposto por Lenneberg (1967). Uma vez que os participantes não deverão apresentar qualquer tipo de diagnóstico de perturbações ao nível cognitivo, apenas foram consideradas as crianças direcionadas pelo psicólogo da instituição escolar como não tendo qualquer perturbação cognitiva através de avaliação objetiva ou que não apresentaram resultados abaixo dos valores médios esperados para a idade cronológica no Teste da Figura Humana (Test du Bonhomme de Goodenough (Pasquasy, 1967)) e no Teste Matrizes Progressivas Coloridas de Raven (Raven, 1947, adaptação portuguesa de Simões, 2000).

Considerando os presentes critérios de inclusão para seleção da amostra, das 87 crianças portuguesas surdas com IC identificadas, foram selecionadas 46, residentes em Portugal Continental, 24 do sexo feminino e 22 do sexo masculino. As 46 crianças foram distribuídas por 5 grupos etários auditivos conforme a sua faixa etária auditiva: 9 crianças dos 2;00 aos 3;11 de idade auditiva $(3 ; 02, \pm .052) ; 9$ crianças dos 4;00 aos 5;11 de idade auditiva $(4 ; 10, \pm .052) ; 9$ crianças dos $6 ; 00$ aos $7 ; 11$ de idade auditiva $(6 ; 10, \pm .053) ; 10$ crianças dos $8 ; 00$ aos 9;11 de idade auditiva $(9 ; 01, \pm .050)$; e 9 crianças dos $10 ; 00$ aos 14;11 de idade auditiva $(11 ; 06, \pm$ 1.40). Para o presente trabalho, as crianças foram ainda caracterizadas de acordo com três variáveis externas: idade de ativação do IC, intervenção precoce em TF; e o tipo de exposição linguística (monolingue oral, bilingue bimodal e exposição à LGP como L2) (ver Quadro 1).

\begin{tabular}{|c|c|c|c|c|c|c|c|c|c|c|c|c|}
\hline \multirow{2}{*}{$\begin{array}{c}\text { Faixa Etária } \\
\text { Auditiva }\end{array}$} & \multirow{2}{*}{$\begin{array}{c}\text { № Por } \\
\text { Faixa }\end{array}$} & \multirow{2}{*}{$\begin{array}{c}\text { Grupo Etário } \\
\text { Auditivo }\end{array}$} & \multirow{2}{*}{$\begin{array}{l}\text { No por } \\
\text { Grupo }\end{array}$} & \multirow{2}{*}{$\begin{array}{l}\text { Idade } \\
\text { Média e } \\
\text { Desvio } \\
\text { Padrão }\end{array}$} & \multicolumn{3}{|c|}{ Idade de Ativação } & \multicolumn{2}{|c|}{$\begin{array}{l}\text { Intervenção } \\
\text { Precoce em TF }\end{array}$} & \multicolumn{3}{|c|}{ Exposição Linguística } \\
\hline & & & & & $1 ; 00-1 ; 11$ & $2 ; 00-2 ; 11$ & $>3 ; 00$ & $\begin{array}{c}\text { TF } \\
\text { Precoce }\end{array}$ & $\begin{array}{l}\text { Sem TF } \\
\text { Precoce }\end{array}$ & $\begin{array}{l}\text { Monol. } \\
\text { Oral }\end{array}$ & $\begin{array}{l}\text { Bilin. } \\
\text { Bimodal }\end{array}$ & $\begin{array}{l}\text { LGP } \\
\text { como } \\
\text { L2 }\end{array}$ \\
\hline $\begin{array}{l}2 ; 00-2 ; 11 \\
3 ; 00-3 ; 11\end{array}$ & $\begin{array}{l}4 \\
5\end{array}$ & $2 ; 00-3 ; 11$ & 9 & $\begin{array}{c}3 ; 01 \\
( \pm .52)\end{array}$ & 5 & 2 & 2 & 6 & 3 & 4 & 3 & 2 \\
\hline $\begin{array}{l}4 ; 00-4 ; 11 \\
5 ; 00-5 ; 11\end{array}$ & $\begin{array}{l}5 \\
4 \\
\end{array}$ & $4 ; 00-5 ; 11$ & 9 & $\begin{array}{c}4 ; 10 \\
( \pm .52)\end{array}$ & 3 & 2 & 4 & 7 & 2 & 2 & 7 & 0 \\
\hline $\begin{array}{l}6 ; 00-6 ; 11 \\
7 ; 00-7 ; 11\end{array}$ & $\begin{array}{l}4 \\
5\end{array}$ & $6 ; 00-7 ; 11$ & 9 & $\begin{array}{c}6 ; 10 \\
( \pm .53)\end{array}$ & 5 & 1 & 3 & 8 & 1 & 4 & 4 & 1 \\
\hline $\begin{array}{l}8 ; 00-8 ; 11 \\
9 ; 00-9 ; 11\end{array}$ & $\begin{array}{l}4 \\
6\end{array}$ & $8 ; 00-9 ; 11$ & 10 & $\begin{array}{c}9 ; 01 \\
( \pm .50)\end{array}$ & 4 & 4 & 2 & 8 & 2 & 3 & 6 & 1 \\
\hline $10 ; 00-14 ; 11$ & 9 & $10 ; 00-14 ; 11$ & 9 & $\begin{array}{c}11 ; 06 \\
( \pm 1.40)\end{array}$ & 1 & 5 & 3 & 7 & 2 & 2 & 7 & 0 \\
\hline & & & & & 18 & 14 & 14 & 36 & 10 & 15 & 27 & 4 \\
\hline
\end{tabular}

Quadro 1. Caracterização das 46 crianças portuguesas surdas com IC da amostra 


\section{i. . Variáveis a analisar}

Os dados recolhidos foram analisados tendo em consideração as variáveis linguísticas e extralinguísticas da população-alvo.

Importa primeiro referir que as capacidades linguísticas orais de crianças surdas com IC devem ser observadas com base na sua idade auditiva, ou seja, de acordo com o período temporal a que estas estão expostas a input auditivo, e não com base na sua idade cronológica. Este critério de análise deverá ser tido em conta em todos os tipos de estudos linguísticos com foco na aquisição e desenvolvimento da língua oral, uma vez que o início da vida auditiva será também o início da aquisição da língua oral.

O impacto da variável idade de ativação do IC na aquisição do movimento-Q será analisado neste estudo, uma vez que nos permite observar os efeitos de três períodos distintos de exposição à língua, relacionando-se com a questão do período crítico. A literatura tem-nos indicado que a população surda implantada após um ano de vida tem défices no movimento sintático (Friedmann \& Stzerman, 2006, 2011). Para este estudo, caracteriza-se a amostra de acordo com três tipos de idade de ativação do IC: crianças com ativação do IC entre 1;00-1;11; crianças com ativação do IC entre 2;00-2;11; e crianças com ativação do IC após os 3;00.

Seguindo o estudo de Friedmann \& Stzerman (2011), que afirmam que uma intervenção precoce em TF, em conjunto com uma implantação precoce, permite que as crianças surdas com dispositivos auditivos tenham desempenhos linguísticos semelhantes aos seus pares ouvintes, observamos a influência da intervenção precoce em TF na aquisição do movimento-Q em interrogativas. Considera-se que uma criança teve uma intervenção precoce em TF quando esta se iniciou antes dos 3 anos de vida (Dunst, 2009; e.o.). Para este estudo, a amostra foi caracterizada por crianças que não tiveram intervenção precoce em $\mathrm{TF}$ e crianças que tiveram intervenção precoce em TF.

O tipo de exposição linguística é uma das variáveis mais pertinentes no estudo do desenvolvimento linguístico oral de crianças surdas com IC, dada a possibilidade de estas poderem ou não ser submetidas a um programa bilingue bimodal (aquisição de uma língua oral e de uma língua gestual nas escolas) (Peterson, Pisoni \& Miyamoto, 2010). Para este estudo, a amostra foi distribuída tendo em conta três tipos de exposição linguística: crianças expostas apenas à língua oral, que neste caso é o PE (exposição monolingue oral); crianças expostas à língua oral (PE) e à língua gestual (LGP) num regime escolar bilingue (exposição bilingue bimodal); e crianças com uma exposição à língua gestual com horário reduzido ( 2 a 4 horas por semana) (exposição à língua gestual (neste caso LGP) como L2). Importa ainda salientar que nenhuma criança do estudo teve acesso à língua oral ou à língua gestual durante o primeiro ano de vida.

\section{b. . Procedimentos e instrumentos}

Para observar a aquisição do movimento-Q em interrogativas em crianças surdas com IC, foi desenvolvido um estudo experimental com base em três tarefas de compreensão e de produção de interrogativas-Q de sujeito (IS), de objeto direto IOD) e de objeto preposicionado (IOP). Os testes aplicados foram adaptados de Baião (2012) e Baião \& Lobo (2014) e incluíram:

i) 1 tarefa de compreensão de interrogativas não $d$-linked (16 IS (8 IS e 8 ISP) e 16 IOD)

ii) 1 tarefa de compreensão de interrogativas $d$-linked (16 IS (8 IS e 8 ISP), 16 IOD e 16 IOP);

iii) 1 tarefa de produção induzida de interrogativas (10 IS, 10 IOD e 10 IOP).

As interrogativas- $\mathrm{Q}$ apresentadas e elicitadas comportam maioritariamente verbos transitivos agentivos de dois lugares (argumento externo e argumento interno (SN ou SP)), contemplando também alguns verbos 
ditransitivos (como o verbo dar). De forma a respeitar a condição de animacidade dos argumentos, estes são representados pelo pronome interrogativo quem em todas as estruturas testadas.

Considerando as assimetrias encontradas na compreensão de interrogativas-Q $d$-linked em crianças ouvintes com desenvolvimento típico e a ausência de sensibilidade à natureza categorial do tipo de constituinte entre IOD e IOP, foi aplicada uma tarefa de compreensão de interrogativas-Q não $d$-linked com $e ́$ que acompanhado pelo constituinte interrogativo Quem deslocado à esquerda (como por exemplo Quem é que o cão está a empurrar?), e uma tarefa de compreensão de interrogativas-Q $d$-linked com um sintagma-Q com um $\mathrm{N}$ foneticamente realizado (como por exemplo Que menino é que o macaco está a abraçar?). As tarefas consistiram na apresentação de duas imagens que incluíam duas personagens com papéis semânticos reversíveis (ver exemplo em Figura 1), e a criança tinha de selecionar a imagem correta após ouvir a interrogativa-Q estímulo.
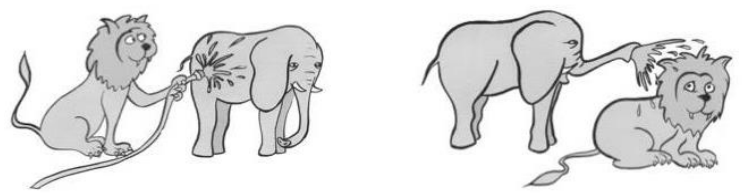

Figura 1. Exemplo de imagens apresentadas nas tarefas de compreensão

Para analisar as competências sintáticas relacionadas com o movimento-Q na produção oral, foi aplicada uma tarefa de elicitação de interrogativas-Q a partir da apresentação de uma imagem com duas personagens em que uma aparecia coberta (ver exemplo em Figura 2). Através da presença de um palhaço, a criança é levada a produzir uma interrogativa-Q, ao mágico, de forma a obter a resposta, como no exemplo seguinte: $O$ gato está a morder alguém, mas eu não sei quem. Pergunta ao mágico.

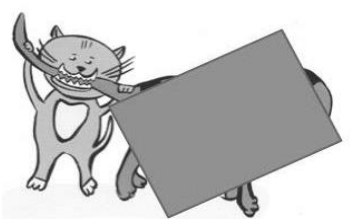

Figura 2. Exemplo de imagem apresentada na tarefa de produção

As três tarefas foram apresentadas através da ferramenta online OpenSesame 3.1 .9 (http://osdoc.cogsci.nl/3.1/), que permite, para as tarefas de compreensão, o registo de seleção da imagem correta ou incorreta após a visualização das imagens em simultâneo com a audição das interrogativas-Q, e, para a tarefa de produção, possibilita a apresentação de imagens. A recolha de dados foi realizada em 1 a 2 sessões, em casa ou na escola, numa sala silenciosa.

\section{Resultados}

Os resultados são apresentados em percentagens de respostas corretas com base nos dados do total da amostra e dos cinco diferentes grupos etários auditivos, de forma a verificar se existem dificuldades na aquisição do movimento-Q em interrogativas-Q, isto é, se há dificuldade com todos os tipos de estruturas interrogativas, incluindo as de sujeito, ou se há apenas dificuldades com as interrogativas de objeto. Para a tarefa de produção de interrogativas-Q, é feita uma análise quantitativa, considerando percentagens de 
respostas em conformidade com a interrogativa-alvo, bem como uma análise qualitativa, considerando os diferentes tipos de respostas.

Para observar o impacto das variáveis linguísticas e extralinguísticas na aquisição do movimento-Q, os resultados são apresentados com base nas três variáveis consideradas para este estudo (idade de ativação do IC, intervenção precoce em TF e o tipo de exposição linguística - monolingue oral, bilingue bimodal e exposição à LGP como L2).

\section{a. Movimento-Q na compreensão e na produção de interrogativas-Q em crianças surdas com IC}

\section{i. . Resultados das tarefas de compreensão}

Nas tarefas de compreensão de interrogativas-Q, verifica-se que não há uma diferença considerável entre IS $(74 \%)$ e IOD $(68 \%)$ em interrogativas-Q não $d$-linked. No entanto, na compreensão de interrogativas-Q $d$ linked, encontram-se assimetrias entre IS (81\%), por um lado, e IOD (58\%) e IOP (65\%), por outro lado (Figura 3). Estas assimetrias são também verificadas em crianças ouvintes com desenvolvimento típico em idades entre os 3 e 5 anos (Cerejeira, 2009; Baião, 2012; Baião \& Lobo, 2014).
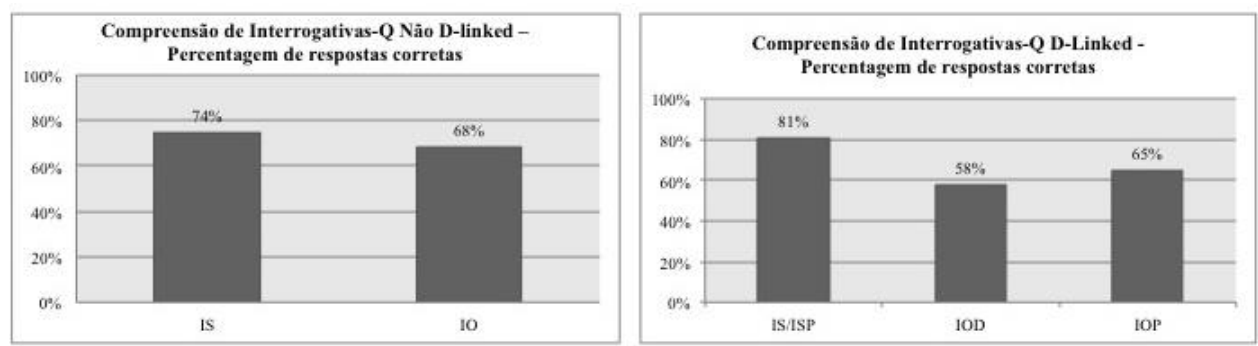

Figura 3. Percentagens de respostas corretas nas tarefas de compreensão de interrogativas-Q não $d$-linked e $d$-linked no total da amostra

De forma a analisar se estas assimetrias estão presentes em toda a população da amostra ou apenas nos grupos etários mais novos, como acontece com a população infantil norma-ouvinte até aos 5 anos de idade (Cerejeira 2009, Baião, 2012), analisámos os dados segundo os grupos etários auditivos presentes na amostra.

Na compreensão de interrogativas-Q não $d$-linked, a população-alvo, em geral, não apresenta valores que se possam considerar assimétricos entre IS e IOD. No entanto, o grupo etário 10;00-14;11 apresenta uma diferença acentuada de $17 \%$ de respostas corretas entre IS (83\%) e IOD (66\%). Ao observar as percentagens de respostas corretas dadas pelas crianças surdas com IC na tarefa de compreensão de interrogativas-Q $d$ linked, parecem existir assimetrias entre IS, por um lado, e IOD e IOP, por outro lado, em todos os grupos etários auditivos. Quando comparamos as percentagens de respostas corretas entre IOD e IOP, verifica-se que, em todos os grupos etários, houve uma percentagem mais alta de respostas corretas nas IOP (Quadro 2). Esta diferença também foi verificada na população infantil norma-ouvinte entre os 4 e os 5 anos de idade, ainda que estatisticamente não tenha mostrado ser significativa (Baião, 2012; Baião \& Lobo 2014). 


\begin{tabular}{|c|cc|cc|cc|cc|cc|} 
Grupo Etário Auditivo & \multicolumn{3}{|c|}{ Interrogativas-Q Não D-linked } & \multicolumn{5}{c|}{ Interrogativas-Q D-linked } \\
& \multicolumn{2}{|c|}{ IS } & \multicolumn{2}{|c|}{ IOD } & \multicolumn{2}{|c|}{ IS } & \multicolumn{3}{c|}{ IOD } \\
\hline $\mathbf{2 ; 0 0}-\mathbf{3 ; 1 1}$ & $111 / 144$ & $77 \%$ & $99 / 144$ & $69 \%$ & $92 / 144$ & $64 \%$ & $69 / 144$ & $48 \%$ & $80 / 144$ & $56 \%$ \\
$\mathbf{4 ; 0 0}-\mathbf{5 ; 1 1}$ & $97 / 144$ & $67 \%$ & $87 / 144$ & $60 \%$ & $101 / 144$ & $70 \%$ & $74 / 144$ & $51 \%$ & $89 / 144$ & $62 \%$ \\
$\mathbf{6 ; 0 0}-\mathbf{7 ; 1 1}$ & $116 / 144$ & $81 \%$ & $99 / 144$ & $69 \%$ & $123 / 144$ & $85 \%$ & $91 / 144$ & $63 \%$ & $112 / 144$ & $78 \%$ \\
$\mathbf{8 ; 0 0}-\mathbf{9 ; 1 1}$ & $137 / 160$ & $86 \%$ & $122 / 160$ & $76 \%$ & $151 / 160$ & $94 \%$ & $112 / 160$ & $70 \%$ & $128 / 160$ & $80 \%$ \\
$\mathbf{1 0 ; 0 0}-\mathbf{1 4 ; 1 1}$ & $120 / 144$ & $83 \%$ & $95 / 144$ & $66 \%$ & $126 / 144$ & $88 \%$ & $82 / 144$ & $57 \%$ & $99 / 144$ & $69 \%$ \\
\hline
\end{tabular}

Quadro 2. Número e percentagem de respostas corretas nas tarefas de compreensão de interrogativas-Q não $d$-linked e $d$-linked com base no grupo etário auditivo

\section{ii. . Resultados da tarefa de produção}

Para a análise das produções obtidas na tarefa de produção de interrogativas-Q, num primeiro momento foram classificadas as estruturas produzidas de acordo com a sua conformidade com a estrutura que se pretendia obter:

(i) respostas com estrutura em conformidade com a interrogativa-alvo (ou seja, produção de IS na condição IS, produção de IOD na Condição IOD, e produção de IOP na condição IOP);

(ii) outras respostas (i.e. interrogativas com alteração de argumentos (produção de IS nas condições IOD e IOP e produção de IOD ou de IOP na condição IS), interrogativas com alteração do tipo de categoria (produção de IODP na condição de IOD, produção de IOD na condição de IOP) interrogativas de sujeito com argumento nulo nas condições IOD e IOP; interrogativas de sujeito com verbo copulativo (ex. Quem é?), interrogativas com um argumento indefinido (ex. A quem penteou alguém?); estruturas declarativas (ex. A vaca morde.) e outras estruturas interrogativas, como interrogativas totais (ex. O rei está a pentear ao menino?).

$\mathrm{Na}$ tarefa de produção, o total da amostra apresenta uma percentagem mais alta de respostas em conformidade com as IS (45\%) quando comparada com as percentagens de IOD (28\%) e de IOP (34\%), pelo que estes dados permitem inferir que pode existir uma assimetria entre as estruturas de sujeito e as estruturas de objeto (direto ou preposicionado). Na tarefa de produção, as IOP apresentam uma percentagem mais alta de respostas em conformidade com a estrutura-alvo do que as IOD (Figura 4).

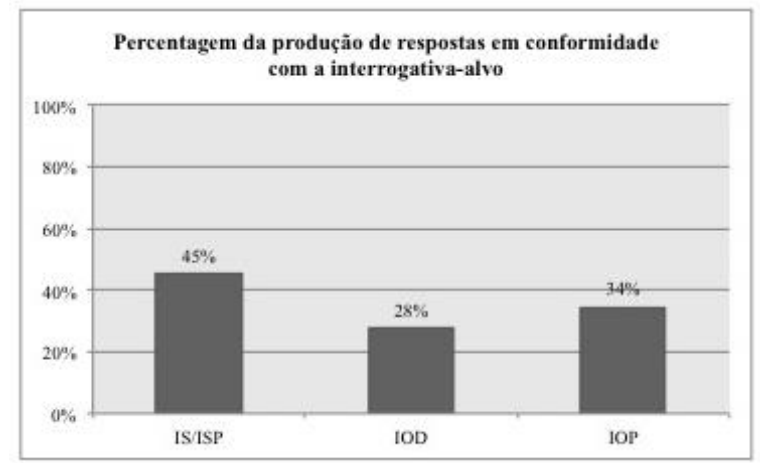

Figura 4. Percentagem de respostas em conformidade com a resposta-alvo no total da amostra

Quando observamos a distribuição da produção de respostas em conformidade com a estrutura-alvo com base nos grupos etários auditivos, verificamos que, embora alguns grupos etários apresentem possíveis assimetrias entre IS e IOD (2;00-3;11: IS com $21 \%$ e IOD com 7\%; 6;00-7;11: IS com 61\% e IOD com 43\%; 
8;00-9;11: IS com 58\% e IOD com 34\%; e 10;00-14;11: IS com 52\% e IOD com 21\%), o grupo dos 4;005;11: IS com 32\% e IOD com 32\% não apresenta assimetrias. Na comparação do desempenho ao nível categorial entre IOD e IOP, verificamos uma percentagem de produção de respostas em conformidade com a estrutura-alvo mais alta quando a condição da estrutura é IOP a partir dos 8;00 anos de idade auditiva (8;009;11: IOD com 34\% e IOP 69\%; 10;00-14;11: IOD com 21\% e IOP com 40\%) (Quadro 3).

\begin{tabular}{|c|c|c|c|c|c|c|}
\hline Grupo Etário Auditivo & \multicolumn{2}{|c|}{ IS/ISP } & \multicolumn{2}{|c|}{ IOD } & \multicolumn{2}{|c|}{ IOP } \\
\hline $2 ; 00-3 ; 11$ & 19 & $21 \%$ & 6 & $7 \%$ & 5 & $6 \%$ \\
\hline $4 ; 00$ - 5;11 & 29 & $32 \%$ & 29 & $32 \%$ & 12 & $13 \%$ \\
\hline $6 ; 00-7 ; 11$ & 55 & $61 \%$ & 39 & $43 \%$ & 36 & $40 \%$ \\
\hline $8 ; 00$ - 9;11 & 58 & $58 \%$ & 34 & $34 \%$ & 69 & $69 \%$ \\
\hline $10 ; 00$ - 14;11 & 47 & $52 \%$ & 19 & $21 \%$ & 36 & $40 \%$ \\
\hline
\end{tabular}

Quadro 3. Número e percentagem de respostas em conformidade com a interrogativa-alvo na tarefa de produção de interrogativas-Q com base no grupo etário auditivo

As respostas dadas em conformidade com a interrogativa-alvo foram maioritariamente gramaticais com base na estrutura geral da interrogativa (presença e posição dos elementos interrogativos). As produções agramaticais de interrogativas por estas crianças corresponderam a: a omissão do elemento que da expressão interrogativa é que quem é que (ex. Quem é o cão está a empurrar?); a utilização incorreta do elemento-Q (ex. A avó está a beijar quê? ); e o uso da preposição incorreta na condição IOP (ex. O macaco bateu para quem?) (Quadro 4).

\begin{tabular}{|c|cc|cc|cc|}
\hline \multirow{2}{*}{ Grupo Etário Auditivo } & \multicolumn{2}{|c|}{ IS/ISP } & \multicolumn{2}{c|}{ IOD } & \multicolumn{2}{c|}{ IOP } \\
& Gramatical & Agramatical & Gramatical & Agramatical & Gramatical & Agramatical \\
\hline \multirow{2}{*}{$\mathbf{2 ; 0 0 - 3 ; 1 1}$} & 15 & 4 & 6 & 0 & 4 & 1 \\
& $79 \%$ & $21 \%$ & $100 \%$ & $0 \%$ & $80 \%$ & $20 \%$ \\
\hline \multirow{2}{*}{$4 ; 00-\mathbf{5} ; \mathbf{1 1}$} & 15 & 4 & 26 & 3 & 8 & 4 \\
& $79 \%$ & $21 \%$ & $90 \%$ & $10 \%$ & $67 \%$ & $33 \%$ \\
\hline \multirow{2}{*}{$\mathbf{6 ; 0 0}-\mathbf{7 ;} ; 11$} & 54 & 1 & 29 & 10 & 29 & 7 \\
& $98 \%$ & $2 \%$ & $74 \%$ & $26 \%$ & $81 \%$ & $19 \%$ \\
\hline \multirow{2}{*}{$\mathbf{8 ; 0 0}-\mathbf{9} ; \mathbf{1 1}$} & 55 & 3 & 34 & 0 & 67 & 2 \\
& $95 \%$ & $5 \%$ & $100 \%$ & $0 \%$ & $97 \%$ & $3 \%$ \\
\hline \multirow{2}{*}{$\mathbf{1 0 ; 0 0}-\mathbf{1 4} ; \mathbf{1 1}$} & 44 & 3 & 16 & 3 & 30 & 6 \\
& $94 \%$ & $6 \%$ & $84 \%$ & $16 \%$ & $83 \%$ & $17 \%$ \\
\hline
\end{tabular}

Quadro 4. Percentagens da gramaticalidade das respostas dadas em conformidade com a interrogativa-alvo

Uma vez que a literatura indica que a população em estudo apresenta défice no movimento sintático, analisamos o tipo de estruturas dadas nas respostas em conformidade com a interrogativa-alvo quando o constituinte era um objeto direto ou um objeto preposicionado.

Em geral, nas respostas produzidas em conformidade com IOD, as estruturas mais produzidas foram as IOD in situ (ex. O gato está a morder quem?) em todos os grupos etários auditivos. Verifica-se um aumento do número de produções de IOD com movimento do constituinte-Q (ex. Quem o cão está a empurrar?; Quem é que o rei está a tapar?) à medida que a idade auditiva aumenta, com exceção do grupo etário auditivo dos 10;00-14;11 que apresenta percentagens de produção de respostas (IOD com movimento do constituinte-Q (32\%) e IOD in situ (68\%)) semelhantes às do grupo dos 4;00-5;11 (IOD com movimento do constituinte-Q (31\%) e IOD in situ (69\%)) (Quadro 4).

Nas respostas produzidas em conformidade com IOP, observa-se que as IOP in situ (ex. A avó lê para quem?) são as estruturas produzidas com maior percentagem em todos os grupos etários auditivos. Embora, no grupo etário auditivo dos 2;00-3;11, se verifique 1 produção de IOP com movimento do constituinte-Q (ex. A quem a girafa bate?; De quem é que o cão está a fugir?), é a partir do grupo dos 6;00-7;11 da presente 
amostra que se verifica a produção de IOP com movimento do constituinte-Q (11\%) em mais do que um participante do grupo (Quadro 5).

\begin{tabular}{|c|cc|cc|}
\hline \multirow{2}{*}{ Grupo Etário Auditivo } & \multicolumn{2}{|c|}{ IOD } & \multicolumn{2}{c|}{ IOP } \\
& mov-Q & Q in situ & mov-Q & Q in situ \\
\hline \multirow{2}{*}{$\mathbf{2 ; 0 0 - 3 ; 1 1}$} & 2 & 4 & 1 & 4 \\
& $33 \%$ & $67 \%$ & $20 \%$ & $80 \%$ \\
\hline \multirow{2}{*}{$\mathbf{4 ; 0 0}-\mathbf{5 ; 1 1}$} & 9 & 20 & 0 & 12 \\
& $31 \%$ & $69 \%$ & $0 \%$ & $100 \%$ \\
\hline \multirow{2}{*}{$\mathbf{6 ; 0 0}-\mathbf{7} ; \mathbf{1 1}$} & 14 & 25 & 4 & 32 \\
& $36 \%$ & $64 \%$ & $11 \%$ & $86 \%$ \\
\hline \multirow{2}{*}{$\mathbf{8 ; 0 0}-\mathbf{9 ; 1 1}$} & 15 & 19 & 8 & 61 \\
& $63 \%$ & $79 \%$ & $12 \%$ & $88 \%$ \\
\hline \multirow{2}{*}{$\mathbf{1 0 ; 0 0}-\mathbf{1 4} ; \mathbf{1 1}$} & 6 & 13 & 9 & 27 \\
& $32 \%$ & $68 \%$ & $25 \%$ & $75 \%$ \\
\hline
\end{tabular}

Quadro 5. Percentagem do tipo de produções em conformidade com IOD e com IOP

Numa análise qualitativa das respostas produzidas, observa-se que as outras respostas produzidas na condição IS variam entre interrogativas de sujeito com argumento nulo (ISAN) (31\%) (ex. Quem é que está a morder?), interrogativas de sujeito com verbo copulativo (Ivcop) (9\%) (ex. Quem é?), interrogativas com sujeito que não correspondem à estrutura-alvo (ISOU) (3\%) (ex. Quem tem uma ferida?), interrogativas com preenchimento da lacuna com um indefinido (Int_Indef) (5\%) (ex. Quem está apontar alguém?) ou com um interrogativo (ex: Para quem o coelho está a ver quem?), interrogativas de outro tipo (OUT) (32\%) (ex. O coelho está?) e declarativas (DECL) (8\%) (ex. O cão mordeu.) (Quadro 6).

\begin{tabular}{|c|c|c|c|c|c|c|c|}
\cline { 2 - 8 } \multicolumn{1}{c|}{} & \multicolumn{7}{c|}{ Outro Tipo de Estuturas Produzidas - Condição IS/ISP } \\
\cline { 2 - 8 } & ISAN & IVCOP & ISOU & Int_Indef & OUT & DECL & NR \\
\hline CondiçãoIS & $31 \%$ & $9 \%$ & $3 \%$ & $5 \%$ & $32 \%$ & $8 \%$ & $12 \%$ \\
\hline
\end{tabular}

Quadro 6. Percentagem dos outros tipos de respostas produzidas na condição IS/ISP

Nas condições IOD e IOP, observa-se também um conjunto de estruturas produzidas diferentes das condições-alvo: interrogativas de sujeito, com inversão dos papéis (IS) (ex. Quem é que está a morder o cão?), interrogativas de sujeito com argumento nulo (ISAN) (ex. Quem está a pintar?), interrogativas de sujeito com verbo copulativo (IvCop), interrogativas de objeto preposicionado com argumento nulo (IOPAN) (ex. De quem está a cuidar?), interrogativas (Int_Indef) com preenchimento da lacuna com um indefinido (ex. *A quem está pintar alguém?) ou com duplicação do pronome interrogativo (ex. Quem o menino agarra quem?), declarativas (DECL) e interrogativas de outros tipos (Quadro 7).

\begin{tabular}{|l|c|c|c|c|c|c|c|c|}
\cline { 2 - 9 } \multicolumn{1}{c|}{} & \multicolumn{6}{c|}{ Outro Tipo de Estruturas Produzidas - Condição IOD e IOP } \\
\cline { 2 - 9 } \multicolumn{1}{c|}{} & IS & ISAN & IvCop & IOPAN & Int_Indef & eclarativ & OUT & NR \\
\hline Condição I OD & $13 \%$ & $31 \%$ & $3 \%$ & $0 \%$ & $8 \%$ & $10 \%$ & $29 \%$ & $6 \%$ \\
\hline Condição I OP & $7 \%$ & $20 \%$ & $4 \%$ & $3 \%$ & $10 \%$ & $8 \%$ & $33 \%$ & $15 \%$ \\
\hline
\end{tabular}

Quadro 7. Percentagem do tipo de produções incorretas nas condições IOD e IOP

\section{b. . Influência das variáveis extralinguísticas na aquisição de interrogativas-Q em crianças surdas com IC}

Como anteriormente referido, as crianças surdas com IC são uma população muito heterogénea tanto no tipo e grau de surdez como nas variáveis linguísticas e extralinguísticas que influenciam direta ou indiretamente o contacto e a aprendizagem de uma língua oral. Para este estudo procurámos observar os dados 
com base em três variáveis que a literatura referencia como as principais influenciadoras no desempenho linguístico desta população: idade de ativação do IC, intervenção precoce em TF e o tipo de exposição linguística (monolingue oral, bilingue bimodal e exposição à LGP como L2). Estes dados devem, contudo, ser considerados com alguma cautela, uma vez que os grupos em comparação têm um número de sujeitos assimétrico (ver Quadro 1 acima).

\section{i. . Resultados com base na idade de ativação do IC}

Quando observamos os dados segundo a idade de ativação do IC nas tarefas de compreensão, verifica-se que a ativação do IC entre 1;00-1;11 e 2;00-2;11 de idade apresenta percentagens com valores semelhantes (entre os $69 \%$ e os $76 \%$ nas duas condições testadas (IS e IO) em interrogativas não $d$-linked). Na tarefa de compreensão de interrogativas-Q $d$-linked verifica-se diferenças entre IS e IOD/ IOP (entre os $80 \%$ e $84 \%$ na compreensão de IS $d$-linked e os $62 \%$ e os $71 \%$ na compreensão de IOD e IOP $d$-linked). As crianças surdas com ativação do IC a partir dos 3 anos de idade apresentam desempenhos inferiores, em particular na compreensão de IOD (43\%) e IOP (56\%) d-linked em comparação com os $67 \%$ de acertos de IOD e $71 \%$ de acertos de IOP das crianças com ativação do IC entre 1;00-1;11 e os 62\% de acertos de IOD e $67 \%$ de acertos de IOP das crianças com ativação do IC entre 2;00-2;11 (Figura 5).
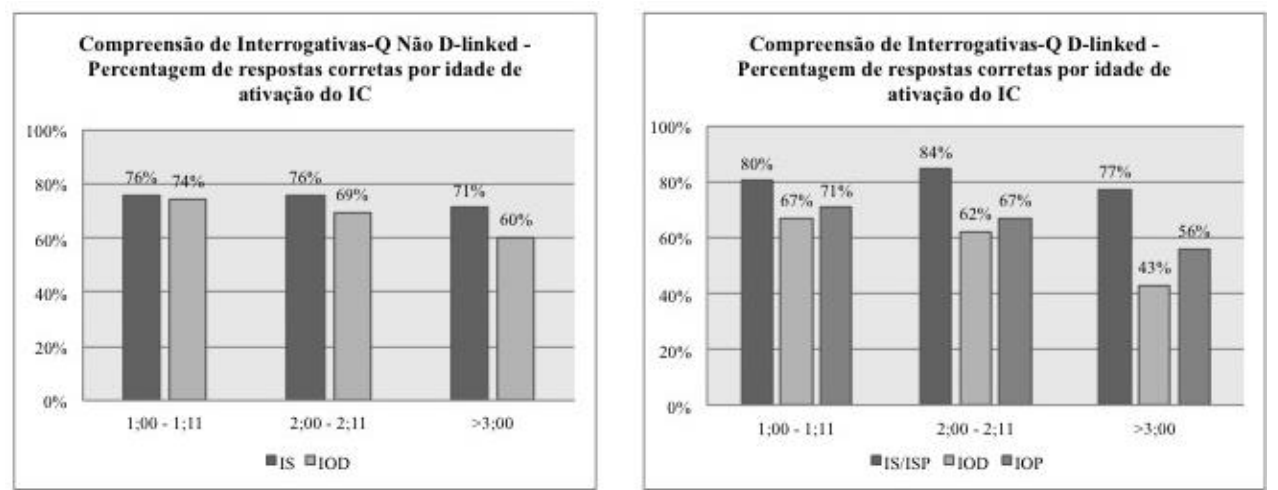

Figura 5. Percentagem de respostas corretas nas tarefas de compreensão considerando a variável idade de ativação do IC

$\mathrm{Na}$ tarefa de produção, verifica-se que as crianças com ativação do IC entre 1;00-1;11 e 2;00-2;11 apresentam melhores percentagens de produção de IS (71\% e 66\% respetivamente) em comparação com as IOD (46\% para ambos os grupos) e as IOP (47\% para 1;00-1;11 e 58\% para 2;00-2;11). As crianças com ativação do IC a partir dos 3 anos apresentam percentagens baixas na produção de IS (44\%) em comparação com as crianças dos outros dois grupos e em comparação com as outras estruturas testadas na mesma tarefa (IOD com 60\% e IOP com 64\%) (Figura 6). Observa-se também que as IOP apresentam uma percentagem de produções em conformidade com o alvo ligeiramente mais alta do que as IOD em todos os grupos tanto na tarefa de compreensão de interrogativas-Q $d$-linked como na tarefa de produção. 


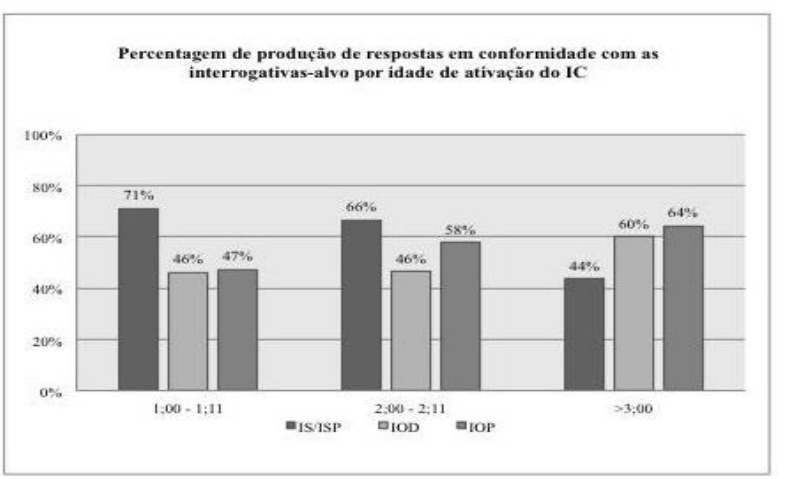

Figura 6. Percentagens de respostas em conformidade com a interrogativa-alvo na tarefa de produção considerando a variável idade de ativação do IC

\section{ii. . Resultados com base na intervenção precoce em TF}

Na observação dos efeitos de uma intervenção precoce em TF nas tarefas de compreensão aplicadas neste estudo, observa-se que, na compreensão de interrogativas-Q não $d$-linked, parece não haver diferenças acentuadas tanto entre as duas condições testadas como entre os dois grupos: crianças sem intervenção precoce em TF com percentagem de $70 \%$ de acertos de IS e de $62 \%$ de IOD e crianças com intervenção precoce em TF com percentagem de $76 \%$ de acertos de IS e de $71 \%$ de IOD. No entanto, as diferenças são visíveis na tarefa de compreensão de interrogativas-Q $d$-linked, em que as crianças que não tiveram intervenção precoce em TF apresentam uma percentagem muito baixa, no valor de $34 \%$ de acertos em IS comparativamente com os $69 \%$ do grupo de crianças que tiveram essa intervenção. Verifica-se também percentagens baixas de acertos em IOD (39\%) e em IOP (46\%) nas crianças sem intervenção precoce em TF comparativamente com o grupo que teve intervenção com 54\% nas IOD e 58\% nas IOP (Figura 7).
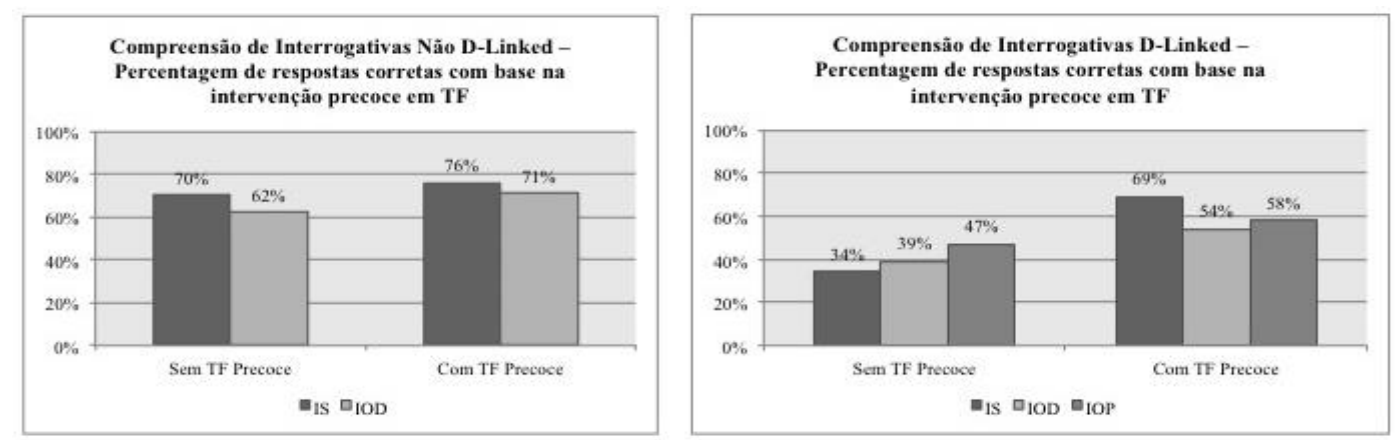

Figura 7. Percentagens de respostas corretas nas tarefas de compreensão considerando a variável intervenção precoce em TF

O desempenho na tarefa de produção apresenta também diferenças entre estes dois grupos de crianças, sendo que as crianças sem intervenção precoce em TF apresentam percentagens mais baixas na produção de respostas em conformidade com IS (27\%), com IOD (24\%) e com IOP (18\%) em comparação com o grupo de crianças que tiveram intervenção precoce em TF com produções em conformidade com IS (51\%), com IOD $(29 \%)$ e com IOP (39\%) (Figura 8$)$. 
As IOP apresentam percentagens ligeiramente mais altas de acertos em comparação com as IOD nas tarefas de compreensão de interrogativas-Q $d$-linked e na tarefa de produção de interrogativas.

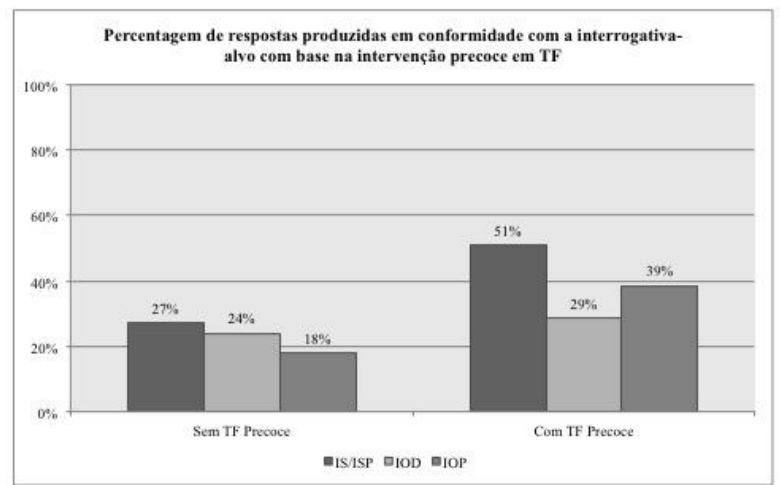

Figura 8. Percentagens de respostas em conformidade com a interrogativa-alvo na tarefa de produção com base na variável intervenção precoce em $\mathrm{TF}$

\section{iii. . Resultados com base no tipo de exposição linguística}

Na observação dos efeitos do tipo de exposição linguística experienciada pelas crianças surdas com IC na tarefa de compreensão de interrogativas não $d$-linked, verificamos que o grupo bilingue bimodal apresenta as percentagens mais baixas de acertos (IS (70\%) e IOD (61\%)) em comparação com as crianças monolingues orais (IS (80\%) e IOD (80\%)) e com as crianças com exposição à LGP como L2 (IS (79\%) e IOD (78\%)). Na tarefa de compreensão de interrogativas $d$-linked, a percentagem de acertos de IS é semelhante entre os três grupos (monolingues orais (84\%), bilingues bimodais (79\%) e expostos à LGP como L2 (79\%). As crianças monolingues orais apresentam um desempenho ligeiramente melhor na compreensão de IOD (67\%) e de IOP (74\%) d-linked em comparação com os valores apresentados pelas crianças com exposição à LGP como L2 (IOD $(63 \%)$ e de IOP (63\%) e das crianças bilingues bimodais (IOD (52\%) e IOP (60\%)) (Figura 9).
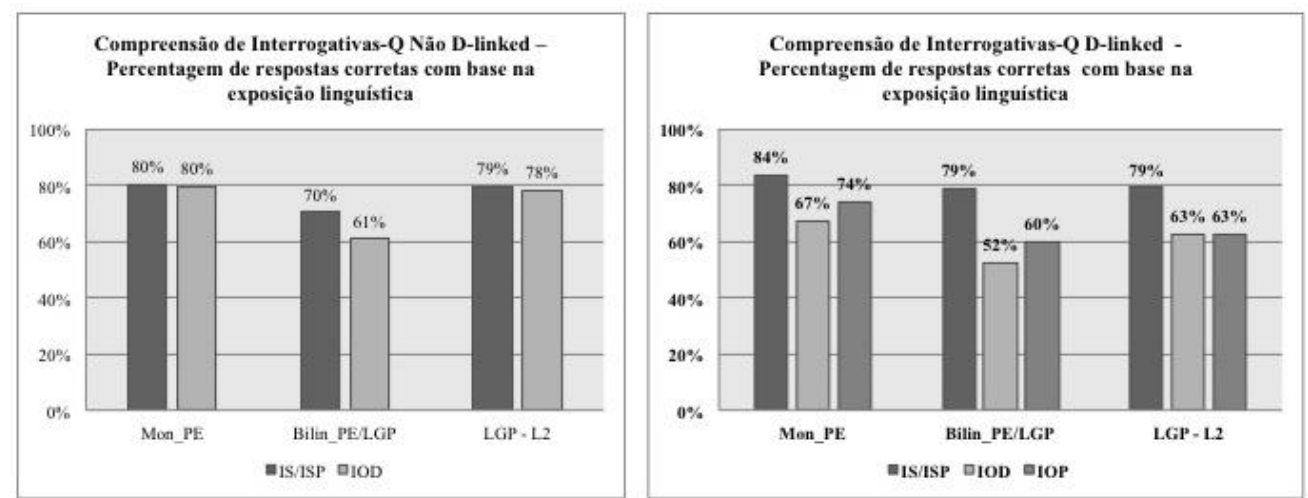

Figura 9. Percentagens de respostas corretas nas tarefas de compreensão considerando a variável tipo de exposição linguística

$\mathrm{Na}$ tarefa de produção, as IS foram produzidas com percentagens mais altas pelas crianças monolingues orais (55\%) e com exposição à LGP como L2 (50\%) do que pelas crianças bilingues bimodais (40\%). Por sua 
vez, a produção de IOD e de IOP aparenta ser mais fácil para as crianças com exposição à LGP como L2 (IOD $(33 \%)$ e IOP (45\%)) e para as crianças bilingues bimodais (IOD (29\%) e IOP (33\%)) do que para as monolingues orais (IOD (24\%) e IOP (33\%)) (Figura 10).

Mais uma vez, as IOP parecem ser estruturas mais fáceis do que as IOD para todos os grupos.

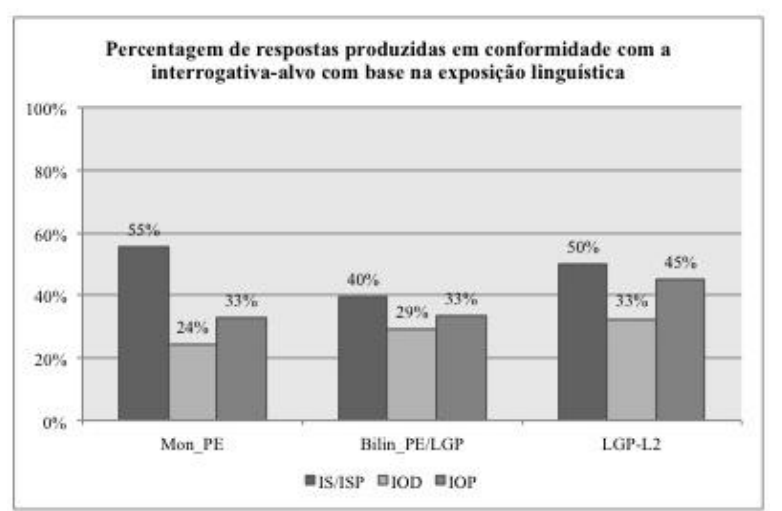

Figura 10. Percentagens de respostas em conformidade com a interrogativa-alvo na tarefa de produção considerando a variável tipo de exposição linguística

\section{Discussão}

a. . Assimetrias na aquisição de interrogativas-Q de sujeito (IS), de objeto direto (IOD) e de objeto preposicionado (IOP) em crianças surdas com IC

A partir do presente estudo, verifica-se que as crianças portuguesas surdas com IC não apresentam assimetrias entre IS e IOD em interrogativas não $d$-linked como é verificado na população infantil normaouvinte entre os 3;00 e os 5;00 anos de idade (Cerejeira, 2009; Baião, 2012). Na compreensão de interrogativas $d$-linked, observa-se que as crianças portuguesas surdas com IC apresentam assimetrias entre IS, por um lado, e IOD/IOP, por outro lado, tal como acontece com a população portuguesa infantil normaouvinte entre os 3;00 e os 5;00 anos de idade (Cerejeira, 2009; Baião, 2012; Baião \& Lobo, 2014). A amostra apresenta a existência de dificuldades na compreensão de IOD e de IOP ao longo de todas as faixas etárias auditivas analisadas (dos 2;00 aos 14;11) em comparação com IS, tal como é observado na população infantil norma-ouvinte, que até aos 5;11 anos de idade apresenta assimetrias entre IS e IOD/IOP (Cerejeira, 2009; Baião, 2012; Baião \& Lobo, 2014).

A ausência de assimetrias entre IS e IO nas interrogativas não $d$-linked e a presença de assimetrias entre IS e IOD/IOP nas interrogativas $d$-linked é expectável para esta população, uma vez que também se verifica na população infantil norma-ouvinte. Tal como referido anteriormente, estas assimetrias corroboram a proposta de Friedmann, Belleti \& Rizzi (2009), que propõem que as dificuldades de aquisição de dependências sintáticas de objeto com movimento do elemento-Q resultam de problemas no estabelecimento da cadeia devido à intervenção de um constituinte (sujeito da interrogativa) que partilha traços semelhantes e que apresenta uma restrição lexical idêntica à do constituinte movido (objeto da interrogativa) (ver também Friedmann, Rizzi \& Belletti, 2016).

$\mathrm{Na}$ observação dos dados com base no total da amostra na tarefa de produção, observamos a possível existência de assimetrias entre IS e IOD/IOP, como é verificado no estudo de Friedmann \& Stzerman (2011), em que as crianças surdas com dispositivos auditivos apresentam mais percentagem de respostas-alvo em IS 
do que em IOD. Nos dados recolhidos no presente estudo, observa-se um aumento na produção de respostas em conformidade com IOD e com IOP à medida que a idade auditiva aumenta. Em comparação com a população infantil norma-ouvinte e de acordo com as idades cronológicas estudadas (3;00 aos 5;11) (Cerejeira, 2009; Baião, 2012; Baião \& Lobo, 2014), a população infantil surda com IC apresenta percentagens de produção mais baixas. Importa, no entanto, salientar que as respostas produzidas em conformidade são, na sua maioria, gramaticais quanto à presença e posição dos constituintes interrogativos. A agramaticalidade das estruturas interrogativas produzidas mais frequente nos dados da amostra resulta da omissão do pronome que do constituinte-Q quem é que (ex. Quem é o cão está a empurrar?).

Em geral, os dados permitem também assinalar que as IOP parecem ser estruturas mais acessíveis para a população-alvo do que as IOD, uma vez que se apresentam com percentagens de acertos mais altas na tarefa de compreensão de interrogativas $d$-linked e de respostas em conformidade com o alvo na tarefa de produção, à semelhança do que é encontrado na população infantil norma-ouvinte portuguesa (Baião, 2012, Baião \& Lobo, 2014).

Em geral, observa-se também que as crianças surdas com IC apresentam percentagens baixas de acertos nas tarefas de compreensão e de produção em conformidade com as estruturas-alvo na tarefa de produção em comparação com a população infantil norma-ouvinte (Cerejeira, 2009; Baião, 2012).

\section{b. . Movimento do constituinte-Q}

Nas tarefas de compreensão de interrogativas-Q não d-linked e d-linked, a população estudada apresenta percentagens de acertos acima dos 50\% na compreensão de IOD e de IOP. Estes dados revelam que, apesar de estas estruturas causarem dificuldades, quando comparadas com as IS/ISP, o movimento sintático do constituinte-Q não é inacessível à população estudada, ao contrário do que é sugerido no estudo de Friedmann \& Stzerman (2011).

$\mathrm{Na}$ tarefa de produção, as crianças portuguesas surdas com IC do presente estudo apresentam preferência na produção de interrogativas de objeto direto e de objeto preposicionado com o elemento interrogativo in situ (ex. A avó está a beijar quem?; A avó está a ler para quem?), tal como é observado no estudo de Friedmann \& Stzerman (2011), em que as estruturas interrogativas in situ prevalecem na tarefa de produção. Esta preferência por IOD in situ e por IOP in situ revela a dificuldade existente no movimento sintático do constituinte-Q nesta população infantil. Verifica-se também que a produção de IOD e IOP com movimento-Q e in situ aumenta à medida que a idade auditiva aumenta. No entanto, o grupo etário auditivo mais velho $(10 ; 11-14 ; 11)$ apresenta produções mais baixas que o grupo etário auditivo $4 ; 00-5 ; 11$, talvez por efeitos do uso de modelos de IC com menos capacidades de discriminação auditiva.

As interrogativas de sujeito e interrogativas de sujeito com argumento nulo são as estruturas com mais percentagem de produção como outras respostas nas condições IOD e IOP, sublinhando a dificuldade no movimento sintático do constituinte-Q objeto ou objeto preposicionado para a população infantil surda com IC estudada. Nas mesmas condições, regista-se também a produção de interrogativas com preenchimento da lacuna com um pronome indefinido ou com a duplicação do elemento interrogativo-Q. Todas estas estruturas foram também encontradas na população surda estudada por Friedmann \& Stzermann (2011), o que parece ser característico desta população.

\section{c. . Variáveis extralinguísticas}

\section{i. . Idade de Ativação do IC}

Na observação dos efeitos da idade de ativação do IC na aquisição de interrogativas-Q, que nos permite estudar o período crítico para a aquisição do movimento-Q, observa-se que as crianças com ativação do IC entre $1 ; 00-1 ; 11$ e 2;00-2;11 apresentam desempenhos semelhantes em todas as tarefas, sugerindo-se que entre 
estes dois períodos a ativação do IC terá os mesmos efeitos. No entanto, não é possível a partir destes dados afirmar que o período crítico para a aquisição do movimento-Q é até aos 2;11, uma vez que a amostra não tem participantes com ativação do IC antes dos 0;11 meses (casos clínicos raros) e não existe uma comparação com uma amostra de controlo de crianças norma-ouvintes no presente estudo. As crianças com ativação do IC a partir dos três anos de idade exibem desempenhos inferiores, em comparação com os outros dois grupos, incluindo na produção de IS, podendo revelar que existem dificuldades específicas com a periferia esquerda da frase (CP) e com o movimento-Q para o domínio funcional. Para uma análise estatística futura, será importante controlar o tempo de uso de IC com a idade de ativação do IC, uma vez que há estudos que indicam que uma criança implantada após os 3 anos de vida poderá atingir um desempenho linguístico semelhante ao dos seus pares ouvintes após 5 anos de uso de IC (Connor et al., 2006; Geers, Nicholas \& Sedey 2003; e.o.).

\section{ii. . Intervenção Precoce em TF}

Ao analisar o impacto da intervenção precoce em TF na aquisição do movimento-Q, verifica-se que, à exceção das interrogativas não $d$-linked, em que ambos os grupos apresentam resultados semelhantes, o desempenho na compreensão de interrogativas- $\mathrm{Q}$ d-linked e na produção de interrogativas- $\mathrm{Q}$ foi realizado com mais sucesso pelas crianças que usufruíram de intervenção precoce em TF, corroborando os resultados de Friedmann \& Stzterman (2011), que indicam esta variável como crucial na aquisição do movimento-Q juntamente com uma ativação do IC precoce. Verifica-se também que as crianças sem intervenção precoce em TF apresentam uma percentagem de acertos muito baixa na compreensão de interrogativas $d$-linked, inclusive nas IS, resultando na ausência de assimetrias entre estas e IOD, IOP.

\section{iii. . Exposição Linguística}

O estudo do impacto dos diferentes tipos de exposição linguística apresenta diferentes efeitos entre tipos de tarefas. Enquanto nas tarefas de compreensão as crianças monolingues orais e as crianças com exposição à LGP como L2 apresentam melhores percentagens nas tarefas de compreensão com assimetrias entre IS e IOD,IOP $d$-linked, as crianças bilingues bimodais apresentam percentagens mais baixas na compreensão de interrogativas não $d$-linked e $d$-linked. Por outro lado, na tarefa de produção, são as crianças expostas à LGP como L2 que apresentam melhores resultados em todos os tipos de interrogativas. As crianças monolingues orais apresentam apenas um desempenho nas IS semelhante às crianças expostas à LGP como L2, mas o seu desempenho nas IOD e nas IOP é inferior aos outros dois grupos analisados. O presente estudo não permite descrever o impacto de uma exposição à língua gestual na aquisição de uma língua oral, apresentando resultados contraditórios entre tipos de tarefas, tal como acontece na literatura (Geers et al., 2017; Davidson, Lillo-Martin \& Pichler, 2014; e.o.). Numa análise posterior a esta variável, será necessário considerar a representação das estruturas interrogativas-Q na LGP para compreender melhor a influência que pode ter a exposição a esta língua.

$\mathrm{Na}$ análise das três tarefas com base nas variáveis i) ativação do IC, ii) intervenção precoce em TF e iii) tipos de exposição linguística, continua-se a verificar que as IOP exibem percentagens mais altas que as IOD, apresentando-se como estruturas mais acessíveis a esta população-alvo independentemente das suas características linguísticas e extralinguísticas.

\section{Conclusões}

O nosso estudo permitiu chegar às seguintes conclusões, corroborando, em grande parte, estudos anteriores realizados para outras línguas: 
i) tal como acontece com as crianças ouvintes, existe assimetria na compreensão de interrogativas $d$ linked de sujeito e de objeto nas crianças surdas com IC, o que leva a crer que esta assimetria decorra de questões gerais de processamento, independentes da população estudada;

ii) existem dificuldades na produção de interrogativas pelas crianças surdas com IC, revelando dificuldades na produção de estruturas com movimento-Q e com dependências sintáticas;

iii) o fator idade de implantação do IC afeta o desempenho: as crianças implantadas após os 3 anos têm desempenhos inferiores aos das dos outros grupos;

iv) o fator intervenção precoce em TF afeta o desempenho: as crianças com TF precoce têm melhores desempenhos dos que as que não têm TF precoce;

v) o fator exposição à língua afeta o desempenho das crianças, ainda que haja diferenças entre as tarefas de produção e de compreensão que terão de ser mais investigadas.

\section{Referências}

Amaral, Diana (2009) Interrogativas-Wh: Periferia Esquerda e Fases. In Actas do XIV Encontro da Associação Portuguesa de Linguística. Lisboa, pp. 61-79.

Augusto, Marina (2005) QU deslocado e QU in situ em PB: aspectos da derivação linguística e questões para aquisição da linguagem. In Anais do IV Congresso Internacional da ABRALIN, pp. 535-546.

Baião, Vera (2012) Aquisição de Interrogativas Preposicionadas em Português Europeu. Dissertação de mestrado, Universidade Nova de Lisboa.

Baião, Vera \& Maria Lobo (2014) Aquisição de interrogativas preposicionadas no português europeu. In Textos Selecionados XXIX Encontro Nacional da APL, Coimbra, pp. 57-70.

Berent, Gerald (1996) Learnability Constraints on Deaf Learners' Acquisition of English Wh-Questions. Journal of Speech and Hearing Research 39, pp. 625-643.

Caselli, Maria, Pasquale Rinaldi, Cristiana Varuzza, Ana Guiliani \& Sandro Burdo (2012) Cochlear Implant in the second year of life: Lexical and grammatical outcomes. Journal of Speech, Language, and Hearing Research 55, pp. 382-394.

Cerejeira, Joana (2019) Aquisição de interrogativas de sujeito e de objeto em Português Europeu. Dissertação de mestrado, Universidade Nova de Lisboa.

Connor, Carol, Holly Craig, Setephen Raudenbush, Krista Heavner \& Teresa Zwolan (2006) The Age at Which Young Deaf Children Receive Cochlear Implants and Their Vocabulary and Speech-Production Growth: Is There and Added Value for Early Implantation. Ear \& Hearing 27, pp. 628-644.

Connor, Carol, Sara Hieber, Alexander Arts \& Teresa Zwolan (2000) Speech, Vocabulary, and the education of children using chochlear implants: oral or total communication? Journal of Speech, Language, and Hearing Research 43 (5), pp. 1185-1204.

Costa, João, Maria Lobo, Carolina Silva \& Elisa Ferreira (2009) Produção e compreensão de orações relativas em Português Europeu: dados do desenvolvimento tipico, de PEDL e do agramatismo. In Actas do XIV Encontro da Associação Portuguesa de Linguística, Lisboa, pp. 211-224.

Costa, João, Maria Lobo \& Carolina Silva (2011) Subject-object asymmetries in the acquisition of Portuguese relative clauses: adults vs. children. Lingua 121.6, pp. 1083-1100.

De Villiers, Jill, Peter De Villiers \& Esme Hoban (1994) The central problem of functional categories in the English syntax of deaf children. In H. Targer-Flusberg (org.) Constraints on language acquisition: Studies of atypical children. Hillsdale, NJ: Erlbaulm, pp. 9-47. 
Davidson, Kathryn, Diane Lillo-Martin \& Deborah Chen Pichler (2014) Spoken English language development among native signing children with cochlear implants. The Journal of Deaf Studies and Deaf Education 19 (2), pp. 238-250.

Dettman, Shani, Elizabeth Wall, Gabriella Constantinescu \& Richard Dowell (2013) Communication outcomes for groups of children using cochlear implants enrolled in auditory-verbal, aural-oral, and bilingual-bicultural early intervention programs. Otology \& Neurotology 34 (3), pp. 451-459.

Dunst, Carl (2009) Early intervention for infants and toddlers with development disabilities. Em S. Odom, R. Horner, M. Snell \& J. Blacher (Orgs.) Handbook of development disabilities. New York: The Guilford Press, pp. 161-180.

Ferreira, Elisa (2008) Compreensão e produção de frases relativas por crianças com Perturbação Específica da Linguagem e por adultos com agramatismo. Dissertação de mestrado, Universidade Nova de Lisboa.

Friedmann, Naama \& João Costa (2011) Resumptive pronouns in hebrew and palestinian arabic hearing impairment. In A. Rouveret (Ed.) Resumptive pronouns at the interfaces. Language Faculty and Beyond: John Benjamins Publishing Company, pp. 223-239.

Friedmann Naama \& Hedva Lavi (2006) On the Order of Acquisition of A-Movement, Wh movement, and V-C movement. In Belletti, Adriana, Elisa Bennati, Cristiano Chesi, Elisa Di Domenico \& Ida Ferrari (Orgs.) Language Acquisition and Development. Newcastle, UK: Cambridge Scholars Press, pp. 211-217.

Friedmann, Naama \& Ronit Szterman (2006) Syntactic movement in orally-trained children with hearing impairment. Journal of Deaf Studies and Deaf Education 11 (1), pp. 56-75.

Friedmann, Naama \& Ronit Szterman (2011) The comprehension and production of Wh-questions in deaf and hard-of-hearing children. Journal of Deaf Studies and Deaf Education 16 (2), pp. 212-235.

Friedmann, Naama, Adriana Belletti \& Luigi Rizzi (2009) Relativized relatives: types of intervention in the acquision of A-bar dependencies. Lingua 119, pp. 67-88.

Friedmann, N., L. Rizzi \& A. Belletti (2016) No case for Case in locality: Case does not help interpretation when intervention blocks A-bar chains. Glossa 2.1, pp. 2-18.

Geers, Ann, Christine Mitchell, Andrea Warner-Czyz, Nae-Yuh Wand, Laurie Eisenber \& The CDaCI Investigate Team (2017) Early sign language exposure and cochlear implantation benefits. Pediatrics 140 (1).

Geers, Ann, Joahanna Nicholas, Emily Tobey \& Lisa Davidson (2016) Persistent language delay versus late language emergence in children with early cochlear implantation. Journal of Speech, Language, and Hearing Research (59), pp. 155-170.

Geers, Ann, Johanna Nicholas \& Allison Sedey (2003) Language Skills of Children with Early Cochlear Implantation. Ear and Hearing 24 (1), pp. 46S-58S.

Grillo, Nino (2009) Generalized Minimality: Feature impoverishment and comprehension deficits in agrammatism. Lingua 119, pp. 1426-1443.

Grillo, Nino (2008) Generalized Minimality: Syntactic Underspecification in Brocas aphasia. LOT.

Grolla, Elaine (2005) A Unified Account for Two Problems in the Acquisition of Pronouns. In John Alderete et al. (Orgs.) Proceedings of the 24th West Coast Conference on Formal Linguistics. Sommerville, MA: Cascadilla Proceedings Project, pp. 173-181.

Guasti, Maria Teresa, Chiara Branchini \& Fabrizio Arozio (2012) Interference in the production of Italian subject and object wh-questions. Applied Psycholinguistics 33 (1), pp. 185-223. 
Hammer, Annemiek, Martine Coene, Johan Rooryck \& Paul Govaerts (2014) The production of Dutch finite verb morphology: A comparison between hearing-impaired CI children and specific language children. Lingua 139, pp. 68-79.

Johnson, Jacqueline \& Elissa Newport (1989) Critical period effects in second language learning: The influence of maturational state on the acquisition of English as a second language. Cognitive Psychology 21 (1), pp. 6099.

Lenneberg, Eric H. (1967) Biological Foundations of Language. New York: John Wiley.

May-Mederake, Birgit (2012) Early intervention and assessment of speech and language development in young children with cochlear implants. International Journal of Pediatric Otorhinolaryngology 76 (7), pp. 939-946.

Mehler, Jacques, Peter Jusczyk, Ghislaine Lamberts, Nilofar Halsted, Josaine Bertoncini \& Claudine AmielTison (1988) A precursor of language acquisition in young infants. Cognition 29 (2), pp. 143-178.

Meisel, Jürgen (2013) Sensitive phases in sucessive language acquisition: the critical period hypothesis revisited. In C. Boeckx \& K. Grohmann (orgs.) The Cambridge handbook of biolinguistics. Cambridge, UK: Cambridge University Press, pp. 69-85.

Moita, Mara (2015) Aquisição do consituinte-Q em crianças surdas com implante coclear: um estudo exploratório. Póster apresentado na UMinho Summer School of Linguistics: Experimental Methods in Syntax, Universidade UMinho.

Moon, Christine, Hugo Lagercrantz \& Patricia Kuhl (2013) Language experienced in utero affects vowel perception after birth: a two-country study. Acta Paedriatrica 102 (2), pp. 156-160.

Pasquasy, R. (1967) Le teste du dessin d'un bonhomme de Fl. Goodenough: Manuel d'interprétation. Bruxelles. Editest.

Pesetsky, David, Esther Torrego (2001) T-to-C Movement: Causes and Consequences. In M. Kenstowicz (ed.) Ken Hale: A Life in Language, Cambridge, Mass: MIT Press, pp. 355-426. Quigley, Stephan \& Peter Paul (1984) Language and Deafness. San Diego, CA: College-Hill Press.

Peterson, Nathaniel, David Pisoni \& Richard Miyamoto (2010) Cochlear implants and spoken language processing abilities: Review and assessment of the literature. Restorative Neurology and Neuroscience 28 (2), pp. 237-250.

Ruben, Robert (1997) A time frame of critical/sensitive periods of language development. Acta Otolaryngol 117, pp. 202-205.

Sauerland, Uli, Kleanthes Grohmann, Maria Teresa Guasti, Darinka Andelkovic, Reili Argus, Sharon ArmonLotem,... Kazuko Yatsushiro (2016) How do 5-year-olds understand questions? Differences in languages across Europe. First Language 36 (3), pp. 169-202.

Simões, Almeida (2000) Investigações no âmbito da aferição nacional do Teste das Matrizes Coloridas de Raven (M.P.C.R.). Lisboa: Fundação Calouste Gulbenkian.

Sell, Fabíola (2002) A aquisição das interrogativas WH in situ em Português Brasileiro. Working papers em Linguistica 6, pp. 56-76.

Soares, Carla (2003) The C-domain and the acquisition of European Portuguese: the case of wh-questions. Probus 15, pp. 147-176.

Soares, Carla (2004) Computation Complexity and the Acquisition of the CP Field in European Portuguese. Proceedings of Console XII, pp. 125-140.

Soares, Carla (2006) La syntaxe de la périphérie gauche en portugais européen et son acquisition. Dissertação de doutoramento, Univ. Paris 8. 
Svirsky, Mario, Ssu-Wooi Teoh \& Heidi Neuburger (2004) Development of Language and Speech Perception in Congenitally, Profoundly Deaf Children as a Function of Age at Cochlear Implantation. Audiology \& NeuroOtology 9 (4), pp. 224-233.

Volpato, Francesca \& Mirta Vernice (2014) The production of relative clauses by Italian cochlear-implanted and hearing children. Lingua, 139, pp. 39-67.

Watson, Linda, Sue Archbold \& Thomas Nikolopoulos (2006) Children's Communication Mode Five Years After Cochlear Implantation: Changes Over Time According to Age at Implant. Cochlear Implants International 7 (2), pp. 77-91.

Wilson, Blake \& Michael Dorman (2008) Cochlear implants: A remarkable past and a brilliant future. Hearing Research 242 (1-2), pp. 3-21.

Yoshinaga-Itano, Christine, Allison Sedey, Diane Coulter \& Albert Mehl (1998) Language of early- and lateridentified children with hearing loss. Pediatrics 102 (5). 